\title{
Dialética do engajamento: uma contribuição crítica ao conceito ${ }^{a}$ \\ Dialectics of engagement: a critical contribution to the concept
}

\author{
- paBlo NABARRETE B A STOS b \\ Universidade Federal Fluminense, Programa de Pós-Graduação Mídia e Cotidiano. Niterói - RJ, Brasil
}

\section{RESUMO}

O objetivo deste artigo ensaístico é contribuir com uma compreensão dialética, crítica e marxiana do conceito de engajamento, aqui localizado e concebido como parte da totalidade. Nossa argumentação, baseada em pesquisa bibliográfica não sistemática, parte dialeticamente da concepção hegemônica sobre engajamento, confrontando-a na perspectiva da totalidade com vistas à sua superação. A compreensão que desenvolvemos nos possibilita fazer a mediação entre o debate epistemológico contemporâneo em ciências da comunicação, com foco nas discussões sobre interações midiatizadas, e a teoria filosófica e política marxiana.

Palavras-Chave: Engajamento, interações midiatizadas, hegemonia

\begin{abstract}
The purpose of this article is to contribute to a dialectical, critical and Marxian understanding of the concept of engagement, hereby addressed and conceived as part of the totality. Our argument, based on non-systematic bibliographic research, starts dialectically from the hegemonic conception of engagement, confronting it from the perspective of totality against a view to overcoming it. The understanding of engagement we have developed enables us to mediate between the contemporary epistemological debate in communication sciences, with a focus on discussions on mediatized interactions, and Marxian philosophical and political theory.
\end{abstract}

Keywords: Engagement, mediated interactions, hegemony 


\section{INTRODUÇÃO}

S NOÇÕES SOBRE engajamento e suas implicações éticas e estéticas,
sobretudo nos campos da ciência e das artes, suscitaram profícuos de-
bates ao longo do século XX. No momento histórico de "ressonância dos efeitos da Segunda Guerra Mundial na Europa”, Jean-Paul Sartre desenvolveu "um texto radical num contexto radical" (Bylaardt, 2013, p. 85), em que formulou sua perspectiva de engajamento no campo das artes, com ênfase na literatura. Sartre (1948/2004) afirma que a prosa, diferentemente da poesia, “é utilitária por essência” (p. 18). Adiante postula que o prosador escolhe determinado modo de ação, que denomina "ação por desvendamento" (p. 20), o que implica os questionamentos sobre que aspectos do mundo se quer desvendar e que mudanças quer proporcionar ao mundo por meio deste desvendamento. “O escritor 'engajado' sabe que a palavra é ação: sabe que desvendar é mudar e que não se pode desvendar senão tencionando mudar" (p. 20). Para Adorno (citado por Bylaardt, 2013), a lei da arte se situa na dialética entre o externo e o interno, que consubstancia a transformação dos elementos internos da obra. Nesse ínterim, o que importa na arte não é seu caráter publicístico e nem a verdade-mensagem, "que se debate entre o que o artista concebeu e a verdade que se quer atribuir objetivamente à obra” (Bylaardt, 2013, p. 87).

Em ensaio sobre engajamento, Eric Hobsbawm (2013) aborda o valor positivo do engajamento para a disciplina científica ou erudita. Para o historiador marxista, o mais decisivo, é que os intelectuais engajados podem ser os únicos "dispostos a investigar problemas ou assuntos que (por razões ideológicas ou outras) o resto da comunidade intelectual não consegue considerar" (p. 188). Hobsbawm argumenta que o engajamento nas ciências sociais é inevitável e que, além disso, as "ciências sociais são essencialmente 'ciências aplicadas", pois destinadas a "transformar o mundo e não somente interpretá-lo" (pp. 189-190), parafraseando a conhecida $11^{\text {a }}$ tese sobre Feuerbach, de Karl Marx. Contudo, o autor pondera que nem todo engajamento político tende a "produzir efeitos inovadores na ciência e na erudição", pois muita erudição engajada é escolástica, trivial e, quando "vinculada a uma estrutura doutrinária ortodoxa, empenhada em provar a verdade predeterminada da doutrina" (p. 191).

$\mathrm{O}$ que constatamos com relação ao conceito de engajamento em diversas publicações na área da comunicação e informação é um uso empirista e reificado do conceito. Não se afirma aqui que falte seriedade aos pesquisadores, pareceristas e editores das publicações analisadas, mas que existe lacuna na reflexão epistemológica sobre o conceito, sobretudo na perspectiva crítica, que, a nosso ver, é estratégica para revelar os atores sociotécnicos, as contradições políticas e de classe que compõem a totalidade na qual as interações midiatizadas 
estão inseridas. Engajamento é concebido nas narrativas e práticas dominantes (Williams, 2005) como aprofundamento e frequência das reações e interações entre instituições e usuários da internet, mediadas por sites de redes sociais (SRS): Facebook, Instagram, Twitter e YouTube, notadamente. Nessa noção, engajamento é sinônimo da performance de uma página ou publicação conforme as métricas dos SRS. O fato de os sentidos dominantes de engajamento se tornarem "senso comum", a concepção mais difundida, mostra a "efetividade histórica” dessa corrente de pensamento dominante (Gramsci, 1968, p. 178).

Vale destacar a contribuição epistemológica e teórica de Rafael Grohmann (2017) para compreensão de engajamento em comunicação e informação. O foco do autor está na maneira como o conceito de engajamento vem sendo compreendido em nossa área, com ênfase nos estudos de recepção. A partir de levantamento bibliográfico, com foco em pesquisadores ingleses do Departamento de Mídia e Comunicações da London School of Economics, cujas análises recaem sobre as relações entre os sujeitos, mídia e sociedade, problematizando estudos de fãs e o "paradigma da participação", Grohmann conclui que há "polissemia da noção de engajamento" (p. 11). Os principais enfoques dos estudos analisados pelo autor são: o engajamento midiático, com visão mais ampla de sociedade e cultura, engajamento com obras, a partir da pesquisa de fãs e antifãs, e o engajamento corporativo. Grohmann conclui que, em meio a tantos sentidos e ausência de reflexividade metodológica, "a noção de engajamento tem o sentido político esvaziado" (p. 11). O comunicólogo aponta o momento dessa "virada discursiva" (p. 4) sobre o sentido de engajamento entre os anos 1990 e 2000, em processo amplo de ressignificação de noções principalmente relacionadas ao mundo do trabalho, como colaborador. Essa ressemantização desloca o lugar de transformação social e luta política do conceito para o de alinhamento com alguma marca, o que denota, para o autor, um alinhamento do conceito de engajamento com o novo espírito do capitalismo, conforme acepção de Boltanski e Chiapello (2009). Também no âmbito da sociologia pragmática, Laurent Thévenot desenvolve a noção de "regimes de engajamento" com o intuito de, em linhas gerais, "modelizar as diferentes relações de proximidade que estabelecemos com o ambiente, da familiaridade ao distanciamento público" (Corrêa \& Dias, 2016, p. 86). Em argumentação semelhante a Grohmann, com ênfase em Marx e também com base em Boltanski e Chiapello, Rute Andrade dos Santos (2019) postula que, para perpetuar o ciclo do capitalismo, a partir da movimentação da produção da mercadoria e a criação do valor por meio do trabalho, o capitalista precisa engajar o trabalhador, o que ocorre por meio da disseminação de ideologias e representações simbólicas que são internalizadas pelo trabalhador e justificam o capitalismo. 
${ }^{1}$ A definição do que é um conteúdo de baixa qualidade ou um título caça-clique é articulada em dados, pesquisas e testes, que buscam dar sustentação a enunciados como este: " $80 \%$ das vezes, pessoas preferem títulos que ajudem a decidir se querem ler todo o texto antes de clicar na postagem" (El-Arini \& Tang, 2014, citado por Araujo, 2018, p. 13).
Em texto publicado no dia 24 de janeiro de 2019, no jornal Folha de S.Paulo, na véspera de o Facebook completar 15 anos, seu fundador e proprietário Mark Zuckerberg tentou explicar ao público brasileiro o modelo de negócio do site e buscou dirimir as polêmicas de 2018 (Arcas, 2019), como violações de privacidade e venda de dados de usuários, abuso das práticas de propaganda, divulgação de informações falsas, subtração de dados pessoais de 30 milhões de contas por hackers e falhas técnicas graves, como instabilidades que permitiram a invasão de contas. No subtítulo do texto, já afirma que "vender dados das pessoas seria contrário a nosso interesse" (Zuckerberg, 2019). Adiante explica que acredita que todos devem ter voz e se conectar, e os anúncios possibilitam ao Facebook oferecer serviços gratuitos. A palavra engajamento é mencionada três vezes. $\mathrm{Na}$ primeira aparição, Zuckerberg se defende sobre o possível "incentivo" à plataforma para aumentarem o "engajamento" (para. 11), pois haveria mais espaço para anúncios. Adiante explica que, do ponto de vista do negócio, é importante que as pessoas fiquem satisfeitas durante seu tempo gasto no Facebook, até para que o usem no longo prazo, por isso, diz que "conteúdos ruins ou caça-clique" geram engajamento no curto prazo, mas seria insensato incentivar essa prática, já que não é o desejo das pessoas (para. 12). E, por fim, diz que não mantém na plataforma conteúdos nocivos porque gerariam engajamento, afinal não é o que as pessoas querem ver. Como é possível perceber no texto do seu fundador, o engajamento, da maneira como é concebido pelo Facebook, é a alma do negócio da plataforma. Quanto maior o número de interações entre as pessoas, empresas, marcas, instituições, quanto mais tempo dedicam à plataforma, mais suas pegadas virtuais alimentam gigantesco banco de dados, que informam os algoritmos para que o conteúdo visualizado, publicitário ou não, mantenha a pessoa conectada e continuamente alimentando o big data.

Etimologicamente, engajamento vem do francês medieval engagier, de en gage, "sob compromisso, sob promessa", de en, "fazer", mais gager, "compromisso, garantia" (https://origemdapalavra.com.br/?s=engajar). Destarte, engajamento evoca ter compromisso com algo. Embora historicamente tenhamos proeminência no uso de engajamento como comprometimento político de sujeitos e práticas que visam à transformação social - intelectual engajado, professor engajado, arte engajada -, mais recentemente se destaca o uso corporativo e publicitário do termo. Nesse ínterim, o conceito de engajamento é utilizado hegemonicamente no mundo do trabalho e na comunicação digital como o alinhamento ideológico entre instituições (principalmente empresas), suas marcas e seus públicos. O Relatório Anual de Engajamento Digital do Consumidor, de 2010, "define engajamento como interações frequentes que fortalecem as relações emocionais, psicológicas ou físicas entre o consumidor e a marca" (Toaldo \& Rodrigues, 2015, p. 5). Raquel 
Recuero (2013) entende engajamento como "uma decorrência do envolvimento das pessoas entre si e com a marca como persona. É a construção de laços mais fortes, de capital social naquele espaço e naquela rede" (para. 3).

O principal objetivo deste artigo, de caráter ensaístico, é contribuir com uma compreensão dialética, crítica e marxiana do conceito de engajamento, aqui localizado e concebido como parte da totalidade. Partimos do pressuposto de que é um equívoco epistemológico e político conceber engajamento exclusivamente circunscrito ao ambiente on-line. Nossa argumentação teórica crítica, baseada em pesquisa bibliográfica não sistemática, é desenvolvida em quatro momentos/movimentos que partem dialeticamente da concepção hegemônica sobre engajamento, confrontando-a na perspectiva da totalidade com vistas à sua superação. Conquanto afirmemos que seja um equívoco epistemológico e político circunscrever engajamento ao ambiente on-line, com o intuito de superar essa noção, realizamos reflexão crítica sobre os conceitos pilares dessa visão dominante, quais sejam, a perspectiva de interação, a vinculação com determinado conteúdo e/ou instituição e a mediação realizada pelos SRS na constituição dessa vinculação. Em um primeiro momento/movimento, inserimo-nos em debate epistemológico sobre o objeto da comunicação, em que se erigem distintas abordagens sobre interação, interação social e interações midiatizadas. Na segunda inflexão, apresentamos uma perspectiva marxiana sobre interação e engajamento. Em seguida, demonstramos como se organizam os aparelhos privados de hegemonia na internet, discutindo sua materialidade a partir dos principais atores sociotécnicos envolvidos nas interações midiatizadas. E, por fim, abordamos a mediação algorítmica do engajamento. A arquitetura dos algoritmos desenha o itinerário de navegação do usuário a partir de suas pegadas digitais, registradas em suas interações cotidianas com aparelhos privados de hegemonia midiatizados, que promovem a vinculação do sujeito por meio de valores, gostos, desejos, ideologia. Na compreensão crítica desenvolvida neste artigo, em última análise, a arquitetura dos algoritmos é definida pela ideologia capitalista, que reflete determinado momento da hegemonia, da luta de classes e das lutas políticas da sociedade. A proposta de compreensão de engajamento que desenvolvemos nos possibilita fazer a mediação entre o debate epistemológico contemporâneo em ciências da comunicação, com foco nas discussões sobre interações midiatizadas, e a teoria filosófica e política marxiana. Queremos contribuir com a reapropriação do caráter político de engajamento a partir de reflexão epistemológica com base teórica crítica.

Raymond Williams (2005) argumenta que a perspectiva de totalidade na teoria cultural marxista surge como proposição alternativa ao uso vulgar de base e superestrutura. Geralmente associada a Lukács, a ênfase em uma 
totalidade de práticas sociais se opõe à "noção estática de base e uma superestrutura consequente" (p. 215). Contudo, o autor pondera que a noção de totalidade pode facilmente ser esvaziada do conteúdo essencial da original proposição marxista, principalmente se não considera os processos de determinação. Dessa maneira, para Williams, a questão-chave a ser colocada em qualquer noção de totalidade na teoria cultural marxista é a noção de intenção. Para o teórico galês, toda sociedade tem organização e estrutura específicas, e os princípios dessa organização se relacionam com intenções sociais, que condicionam nossa definição de sociedade conforme o domínio de determinada classe. Williams (2005, p. 216) argumenta ainda que, para a noção de totalidade ser corretamente utilizada, precisamos combiná-la com o conceito de hegemonia, algo em que a consciência de determinada sociedade se encontra profundamente imersa, e que enfatiza o fato da dominação.

A partir da compreensão formulada por Lukács, de que a ideologia constitui o medium que possibilita à práxis política ultrapassar o interesse imediato de classe e alcançar o momento socialmente universal, Carlos Nelson Coutinho (1992) atesta que, em termos gramscianos, "isso significa dizer que a ideologia é o medium da hegemonia" (p. 66). O processo que compreendemos como engajamento se constitui na vinculação social, afetiva e gustativa do sujeito com determinada ideologia, portanto se configura como dimensão comunicacional e sensível atuante no engendramento da hegemonia. Em termos gerais, a vinculação social se estabelece na sociabilidade cotidiana, nas práticas e processos socioculturais que medeiam a construção de sentidos. Nesse ínterim, podemos dizer que há retroalimentação entre os filtros bolha (Pariser, 2012), constituídos pelo sistema de algoritmos, e as bolhas constituídas na sociabilidade cotidiana, nas interações sociais dos indivíduos em espaços, grupos e instituições como empresa, escola, família, amigos, igreja, bairro, sindicatos, partidos políticos, movimentos sociais etc. Como propõe Agnes Heller (2004), a assimilação imediata das formas de comunicação social ou intercâmbio ocorre por meio dos "grupos", que realizam a mediação entre "o indivíduo e os costumes, as normas e a ética de outras integrações maiores" (p. 19). A vinculação afetiva e gustativa é a dimensão do envolvimento objetivo e subjetivo do sujeito com determinada ideologia, envolve a dimensão estética e sensível que denota a concretude de determinada ideologia na práxis. Se o indivíduo gosta de determinada organização e do conteúdo desenvolvido por ela, pressupõe-se determinado conhecimento anterior para a formação deste gosto, a existência de determinações econômicas, sociais e culturais, o vínculo com determinada ideologia, cada vez mais midiatizada. Muniz Sodré (2002) compreende a vinculação entre sujeitos, na luta pela hegemonia política e econômica ou no empenho ético de reequilíbrio 
das tensões comunitárias, como o núcleo teórico da comunicação. Vinculação para Sodré é "a radicalidade da diferenciação e aproximação entre os seres humanos" (p. 223). Nossa perspectiva é que o engajamento é erigido na fricção entre o ser e a consciência social e política mediante interações sociais cotidianas mediadas e midiatizadas por aparelhos privados de hegemonia. Na dialética do engajamento, temos o sentido hipostasiado do conceito na sua relação com as infotelecomunicações ${ }^{2}$ (ITCs) (Moraes, 2000) e temos a possibilidade crítica e conscientemente política da construção do engajamento por meio da educação crítica e da prática política.

\section{COMUNICAÇÃO, INTERAÇÃO E MIDIATIZAÇÃO}

A centralidade das interações sociais e seus processos simbólicos na compreensão e construção do objeto comunicacional perpassa a história das teorias da comunicação. Temos clareza do intervalo histórico de quase um século de desenvolvimento das forças produtivas, das infotelecomunicações, que separa as primeiras contribuições do campo dos atuais debates sobre interação social e comunicação. Não obstante, é possível identificar implicações epistemológicas dos estudos desenvolvidos na Escola de Chicago nos debates mais recentes em ciências da comunicação, embora estes primeiros estudos nem sempre sejam lembrados. Não há consenso sobre a Escola de Chicago ser considerada uma escola de comunicação ${ }^{3}$. Marcada pelo ecletismo teórico e metodológico, com contribuições marcantes para a formação das disciplinas sociologia, antropologia e psicologia social, foi na Escola de Chicago que se desenvolveu a perspectiva teórica do interacionismo simbólico. O filósofo George Herbert Mead é o precursor dessa vertente, geralmente associada à psicologia social, cujo interesse principal é a relação entre a mente, o self e a sociedade. Entretanto, quem cunhou o nome interacionismo simbólico e estruturou seus principais pressupostos foi o aluno de Mead: Herbert Blumer.

Howard Becker (1996, p. 183), que pertenceu à Escola de Chicago, alerta para o fato de que o livro principal de Mead, Mente, self e sociedade, publicado em 1934, seja praticamente ilegível. Isso porque foi montado a partir de aulas ministradas por Mead, pois seus alunos chegaram à conclusão de que ele não escreveria o livro. O sociólogo também salienta que a noção de interação simbólica possui nunances e compreensões distintas, sendo uma das ideias predominantes a oposição às noções de organização social e estrutura social. Howard Becker compreende que a unidade básica de estudo para compreender qualquer organização social é a interação social: "pessoas que se reúnem para fazer coisas em comum” (p. 186). Herbert Blumer (1980) salienta que o interacionismo
${ }^{2}$ Este conceito, cunhado por Dênis de Moraes (2000), reúne três setores convergentes (informática, telecomunicações e comunicação) para designar a reunião de poderes estratégicos em conglomerados multimídia, que acumulam patrimônios e lucros sem precedentes. Optamos por este conceito a partir da leitura das discussões sobre dialética do gosto, na obra de Marco Schneider (2015).

${ }^{3}$ Dois dos principais livros que compõem a literatura da área, Teorias da comunicação, de Mauro Wolf (2006), e História das teorias da comunicação, de Armand Mattelart e Michèle Mattelart (2006), adotam compreensões distintas. Enquanto no primeiro livro a Escola de Chicago não é mencionada, no segundo é apresentada como a primeira escola da comunicação. 
${ }^{4}$ Nesse ínterim, concordamos com Sodré (2002) quando afirma que "mesmo do ponto de vista estritamente material, mutação tecnológica parece-nos expressão mais adequada do que 'revolução',

já que não se trata exatamente de descobertas linearmente inovadoras, e sim de maturação tecnológica do avanço científico, que resulta em hibridização e rotinização de processos de trabalho e recursos técnicos já existentes sob outras formas (telefonia, televisão, computação) há algum tempo" (p. 13). simbólico se baseia, em última análise, em três premissas. "A primeira estabelece que os seres humanos agem em relação ao mundo fundamentando-se nos significados que este lhes oferece" (p. 119). Esses significados provêm de todos os elementos que podem ser observados em seu universo: objetos físicos, pessoas, instituições, além de situações cotidianas. A segunda premissa estabelece que os significados desses elementos são erigidos na interação social com as demais pessoas. A terceira premissa consiste no processo interpretativo que condiciona a produção de sentido com relação aos elementos que se entra em contato. Conquanto possamos perceber o destaque dado ao papel interpretativo do indivíduo, a primeira premissa destaca a materialidade do universo e sua determinação para a compreensão da realidade.

Com o intuito de explorar as modalidades de situações interativas provocadas pelo uso dos meios de comunicação, o sociólogo estadunidense John B. Thompson (2002) distingue inicialmente três tipos de interação: “interação face a face", "interação mediada" e "quase-interação mediada" (p. 78). A ideia central da proposta teórica de Thompson (2018), de teoria interacional da mídia, é que, para analisar os meios de comunicação e seus impactos, temos que avaliar os tipos de ação e interação provocados por estes meios. Com o crescimento da internet e outras formas de comunicação em rede - processo que Thompson (2018) e outros compreendem como "revolução digital", mas preferimos o termo mutação digital $^{4}$-, o autor propõe um quarto tipo de interação, a "interação mediada on-line", que é a comunicação mediada por computador, independentemente da característica do suporte técnico, e destaca os SRS como o "cenário perfeito" para esse tipo de interação (p. 20). Como as demais formas de interação mediada, a interação mediada on-line provoca a extensão das relações sociais no tempo e no espaço e diminui as possibilidades de deixas simbólicas. Comparando com a quase-interação mediada, Thompson destaca o caráter dialógico desta mais recente possibilidade de interação midiatizada. Conquanto, mais adiante, Thompson problematize esta afirmação ao atestar que este caráter dialógico da interação mediada on-line ocorre "pelo menos potencialmente" (p. 21), este é um aspecto nevrálgico para tensionarmos a concepção de engajamento como corolário de interações midiatizadas. Esses argumentos serão mais bem desenvolvidos nos próximos tópicos, mas torna-se importante neste momento problematizarmos o potencial dialógico, comunicativo, da interação mediada on-line. Se compreendermos diálogo na perspectiva freirena, em que não pode haver encontro entre "inconciliáveis", tampouco "invasão cultural dialógica" (Freire, 1977, p. 43), nem conquista dialógica, porque são termos excludentes, há muitas limitações econômicas, sociais, políticas e tecnológicas ao diálogo na interação mediada on-line. Em alguns momentos, Thompson (2018) trata mais 
especificamente das questões de poder que estruturam as interações mediadas e midiatizadas, principalmente ao mencionar que nem todas as pessoas e organizações possuem o mesmo poder para tornar visível um texto, imagem ou vídeo, o que depende de recursos, e ao afirmar que essas novas plataformas também atuam como gatekeepers.

A perspectiva da interação social como fundamento da comunicação, da produção de sentido entre sujeitos, pode ser também identificada, com matizações teóricas diversas, nos debates epistemológicos desenvolvidos neste século no Brasil. Em artigo que apresenta resultados preliminares da metapesquisa A construção do capital teórico sobre os processos de interação midiatizada nos artigos científicos apresentados nos encontros nacionais da Compós durante a década de 2000, Maria Ângela Mattos e Ricardo Costa Villaça (2012) se propõem a "enriquecer a discussão sobre as perspectivas teórico-conceituais da interação midiatizada a partir das contribuições dos autores de referência do campo comunicacional" (p. 23). Os autores atestam que, embora esse conceito tenha entrado em pauta no início da década passada, ainda há diversidade de usos, apropriações, dispersão e falta de clareza conceitual. Vera França propõe o que a própria autora denomina como paradigma relacional (ou interacional) da comunicação, em que o fenômeno comunicacional é compreendido como o processo de compartilhamento simbólico e não como transmissão de mensagens. Nessa perspectiva, França coloca a questão da interação como objeto da comunicação, como paradigma teórico (Mattos \& Villaça, 2012). Coadunando com essa mirada, o artigo de Lucrécia Ferrara "Epistemologia da comunicação: além do sujeito e aquém do objeto", publicado no livro Epistemologia da comunicação (2003), também destaca o conceito de interação para o debate epistemológico do campo da comunicação. Ferrara propõe "uma epistemologia das relações comunicativas, em vez de uma epistemologia da comunicação. Em outras palavras, a autora propõe uma epistemologia das trocas comunicativas, superando a natureza das mídias e suportes enquanto núcleos temáticos" (Mattos \& Villaça, 2012, p. 27), interrogando a processualidade das mídias nas relações comunicativas.

José Luiz Braga defende a perspectiva de que os estudos de comunicação podem ser definidos pelo objeto processos de interação social. O autor propõe um terceiro sistema, para além da produção e recepção de mensagens, o sistema de resposta, da circulação de sentidos, a interação social sobre a mídia. Diferentemente de outros autores, a perspectiva de interação social de Braga (2006a) adota a centralidade dos processos de midiatização na configuração da interação social. Esse processo de interação social sobre a mídia é um "sistema de circulação diferida e difusa" (p. 27). Os sentidos circulam entre pessoas, grupos 
${ }^{5}$ Não é nosso principal objetivo aqui ampliar e aprofundar o debate epistemológico sobre midiatização, mas dialogar com alguns autores a partir de perspectiva marxiana. Um bom panorama das principais tendências de abordagens sobre mediação e midiatização pode ser encontrado em Mattos, Janotti e Jacks (2012). e instituições compondo a cultura. José Luiz Braga contribui sobremaneira com nossa discussão sobre a concepção de engajamento on-line como volume de interações mediadas pela internet e por SRS, ao argumentar que as "respostas" das interações midiatizadas na internet também são diferidas e difusas. Portanto, torna-se um equívoco epistemológico e político conceber como engajamento o volume de interações midiatizadas sem verificar a circulação e produção de sentido para além do ambiente on-line, sem investigar a maneira como o vínculo com narrativas e/ou instituições se realiza nas interações sociais cotidianas.

A internet, na verdade, viabiliza e/ou acelera e amplia aquilo que assinalamos como "interatividade difusa": as "respostas" não são tipicamente de retorno direto pontual (interatividade "conversacional") - são antes repercussão - redirecionamento - circulação de reações para âmbitos diferidos e difusos. Nessa circulação, é claro que o polo emissor acaba também entrando no circuito (e o faz até no seu próprio interesse de sintonia). Mas é claro que, aí, recebe as respostas de um modo completamente diferente daquele que seria associado a um retorno ponto a ponto. Trata-se, agora, de recebimento de alguma coisa que se tornou "social" (disponível em modo diferido e difuso). Ou seja - as respostas desenvolvidas pelo sistema interacional mediático, mesmo com o desenvolvimento de tecnologias digitais ponto a ponto, são respostas potencialmente diferidas e difusas. A “impressão" de conversacionalidade é antes uma lógica de sistema para viabilização da inserção de "tipo individual”. (Braga, 2006b, p. 22)

O conceito de midiatização ${ }^{5}$ vem ocupando papel de destaque nos estudos em comunicação desde o início deste milênio, em diferentes países e com matizes diversos, notadamente na produção de autores europeus e latino-americanos. Em âmbito social específico, a palavra midiatização pode ser compreendida como processo no qual diferentes instâncias sociais - política, entretenimento, educação - operam segundo lógicas da mídia. Em nível macro, podemos falar da midiatização da própria sociedade, perspectiva que vem se destacando nas reflexões da área comunicacional (Braga, 2006b,). Stig Hjarvard (2014) entende midiatização como um processo de dupla face, em que a mídia se transformou em instituição semi-independente e à qual as demais instituições precisam se adaptar. Além disso, a mídia, tanto pelos meios de comunicação interativos como através dos meios de comunicação de massa, já se integrou ao cotidiano de outras instituições como política, família, trabalho e religião. Fausto Neto (2008) atesta que não se trata apenas de reconhecer a centralidade da mídia nos processos interacionais entre os campos sociais, mas de constatar que o próprio funcionamento da sociedade, suas práticas, lógicas e códigos são atravessados e permeados pela lógica da "cultura da mídia" (p. 92). Braga (2006b) afirma que a 
"mediatização" está em marcha para se tornar o que ele define como "processo interacional de referência" (p. 11). Na argumentação do autor, isso não significa que a cultura escrita como processo interacional será anulada, mas que a "cultura mediatizada" constitui processualidades que passam a funcionar como "organizador principal da sociedade". Sobressai nos debates a preocupação em entender como a midiatização implica novos padrões de interação entre os sujeitos individuais e coletivos, e destes com a realidade e o mundo, constituindo uma nova "ambiência interacional" (Fausto Neto, 2008, p. 95).

Dialogando com a perspectiva de Braga (2006a, 2006b), argumentamos que a construção de engajamento requer a construção de vínculos sociais, afetivos e gustativos, o que exige a investigação de como se articulam as interações sociais no cotidiano das pessoas, nas suas práticas sociais, a partir da sua imersão nesta "ambiência interacional". Engajamento não se realiza somente por tecnointeração, processo caracterizado pelo medium, que Muniz Sodré (2002) define da seguinte maneira:

trata-se de dispositivo cultural historicamente emergente em que o processo da comunicação é técnica e industrialmente redefinido pela informação, isto é, por um regime posto quase que exclusivamente a serviço da lei estrutural do valor, o capital, e que constitui propriamente uma nova tecnologia societal (e não uma neutra "tecnologia da inteligência") empenhada num outro tipo de hegemonia ético-política. (pp. 21-22)

Podemos compreender midiatização como a dilatação da lógica das ITCs na mediação e organização da realidade, na relação entre os sujeitos e o mundo, o que certamente erige novos padrões de interação, o que implica também novas formas de se inserir e apreender a realidade, ou seja, há implicações e imbricações da midiatização no arranjo ideológico pelo qual concebemos a realidade. Muniz Sodré (2014) recorre aos Gundrisse de Marx, mais precisamente ao processo de formação dialético do capital, em argumento no qual defende a comunicação "como principal forma organizativa" (p. 14). Nos Gundrisse, Marx (2011) distingue o capital geral de categorias como trabalho, valor, dinheiro, para destacar a necessidade de "fixar a forma determinada" em que o capital é posto em "certo ponto" (Sodré, 2014, p. 14). Ao trazer a discussão para o campo da comunicação, nesse "certo ponto", conforme Sodré, os signos, discursos e dispositivos técnicos "são os pressupostos do processo de formação de uma forma nova de socializar, de um novo ecossistema existencial em que a comunicação equivale a um modo geral de organização" (p. 14). 


\section{INTERAÇÃO E ENGAJAMENTO EM PERSPECTIVA MARXIANA}

A centralidade da compreensão de interação em perspectiva marxiana está na ontologia do ser social: na mirada da interação como práxis e como mediação para a unidade política e de classe. Marx e Engels (2012) argumentam que a história dos homens deve ser estudada e elaborada em conexão com a história material e as interações sociais. Um aspecto histórico e ontológico é o fato de que a produção da história e da vida material envolve relação social: "desde o início manifesta-se, pois, uma dependência material dos homens entre si, condicionada pelas necessidades e pelo modo de produção" (p. 56). Marx e Engels concluem que o homem possui também "consciência", mas "consciência real, prática”, que é a linguagem. Em outras palavras, de uma perspectiva materialista dialética, enquanto o trabalho possibilita o intercâmbio material com a natureza, o desenvolvimento das forças produtivas e a criação de valor, a linguagem atende a necessidade de intercâmbio, de comunicação entre os homens, e os constitui.

Outra maneira de conceber a interação social, também conforme a ontologia materialista, está na relação entre interação e política. Lukács superou, dialeticamente, a teoria de Marx sobre interação ao mostrar que, nas formas mais evoluídas de práxis social, de trabalho, ganha destaque a "ação sobre outros homens" (Coutinho, 1992, p. 63) também no sentido da adoção de determinadas posições teleológicas. Coutinho vai denominar esse desenvolvimento ontológico da interação de práxis interativa, a dimensão política da práxis social. O filósofo político brasileiro destaca a dimensão do convencimento, das normas e valores inerentes à práxis interativa, no agir sobre a ação de outro. Nesse aspecto, por envolver normas e valores, o conhecimento envolvido na práxis interativa não possui eficácia somente como ciência, como reprodução do real. Conforme Coutinho, Gramsci denomina como ideologia esse conhecimento próprio da práxis interativa. "Portanto, para Gramsci, a ideologia - enquanto concepção de mundo articulada com uma ética correspondente - é algo que transcende o conhecimento e se liga diretamente com a ação voltada para influir no comportamento dos homens" (p. 65). Ainda de acordo com Coutinho, o reconhecimento de que na práxis interativa a consciência mobilizada é de tipo axiológico é "uma contribuição essencial para a compreensão ontológica da práxis política, que é uma esfera decisiva da interação social em geral" (p. 65).

A acepção mais difundida de ideologia, conforme Marx e Engels (2012), é a de inversão da realidade: "em toda ideologia, a humanidade e suas relações aparecem de ponta-cabeça” (p. 51). Mas Marx demonstrou em outras passagens a importância de se compreender ideologia na sua concretude, na existência real dos homens. Destacamos aqui a conhecida passagem em que o autor afirma que são pelas formas ideológicas - jurídicas, políticas, religiosas, artísticas ou 
filosóficas - que os homens adquirem consciência e que é preciso "explicar a consciência pelas contradições da vida material, pelo conflito que existe entre as forças produtivas e as relações de produção" (Marx, 2008, p. 48). Desse modo, precisamos compreender a relação concreta entre consciência, representação e realidade. Autores como Lênin, Gramsci, Lukács e Mészáros levaram a cabo a tarefa teórica de compreender ideologia na sua concretude, como conjunto de ideias que sustentam e mobilizam a práxis social, como cosmovisão adequada a uma ética. Pelo método dialético, mesmo se tratando de "falsa consciência", conforme se referiu Engels em carta a Mehring, esta precisa ser concretamente estudada conforme a etapa e totalidade histórica a que pertence (Lukács, 1974, p. 63). Na mesma obra, Lukács afirma adiante que os momentos ideológicos não apenas encobrem ou distorcem os interesses econômicos, não são apenas "bandeiras e palavras de ordem", mas são "parte integrante e elementos da própria luta real” (p. 73).

A partir do postulado de Jorge Larrain de que há na literatura marxista duas linhas gerais do termo ideologia, uma negativa, associada à acepção originária de Marx, e outra neutra, Marco Schneider (2015), concordando com Larrain, defende a complementaridade de ambas as abordagens de ideologia na análise de um fenômeno político ou cultural, o que enriquece o estudo dialético, segundo o autor. Vale resgatar aqui o problema e argumento central da obra de Schneider, que são fecundos para balizar nossa compreensão de engajamento. Na proposta de um estudo dialético do gosto, o autor parte do problema central da "captura do gosto pelo capital" (p. 36). O gosto é compreendido dialeticamente como "expressão e medida do valor de uso de bens, materiais e simbólicos", e também como "substrato sensível das ideologias". Dessa maneira, argumenta Schneider, se a informação midiatizada é a principal responsável pela formação dos gostos na sociedade contemporânea, esta possui dimensão estética e ético-política mais profunda do que se pensava. Ao levar a reflexão para as compreensões neutra e negativa de ideologia, o autor postula que, conforme a acepção neutra, os juízos de gosto contêm elementos ideológicos em narrativas que dão sentido às práticas gustativas dos sujeitos; e conforme a acepção negativa, as mesmas práticas gustativas, sustentadas em relações de subordinação e exploração entre sujeitos, são mascaradas e distorcidas por articulações discursivas. Podemos compreender dialeticamente o gosto como gatilho para o engajamento, para a vinculação do sujeito com determinada ideologia; e a compreensão dos processos histórico e social de formação deste gosto, considerando o papel das ITCs, dos aparelhos privados de hegemonia e os imperativos da produção, como caminho para o engajamento crítico. Conforme Mészáros (1993), "a consciência pode 


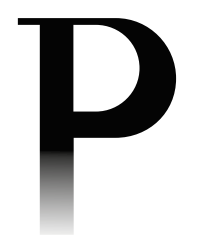

ser colocada a serviço da vida alienada, da mesma forma que pode visualizar a suplantação da alienação" (p. 79).

A argumentação de Karel Kosik (1976), baseada no conceito de fetichização da mercadoria em Marx, permite-nos refletir sobre a concretude do engajamento reificado e projetar nossa compreensão de engajamento crítico. O filósofo marxista tcheco inicia e conclui seu livro mais conhecido, Dialética do concreto, afirmando que a dialética trata da coisa em si, que não se manifesta imediatamente ao homem. A "coisa em si" é o homem e seu lugar no universo, é a totalidade do mundo revelada pelo homem na história e o homem que existe na totalidade do mundo (p. 250). Kosik denomina como práxis utilitária e como práxis fetichizada a maneira fragmentária como os homens se inserem na divisão do trabalho, como concebem suas representações de mundo a partir das formas fenomênicas da realidade, sem contudo, adentrarem na essência dos fenômenos. $\mathrm{O}$ autor vai desenvolver sua compreensão de engajamento como estado de preocupação do sujeito, da sua inserção na práxis utilitária cotidiana, nas suas relações sociais, na práxis determinada. Conforme Kosik, as relações objetivas determinam o sujeito, que se comporta como indivíduo orientado pela "preocupação" (p. 73). A preocupação é a inserção do indivíduo no sistema das relações sociais, sob seu engagement e sua práxis utilitária; é a ação deste indivíduo como solicitude e preocupação; enfim, é também o sujeito que se manifesta em sua ação como indiferenciação e anonimidade. "O indivíduo se move em um sistema formado de aparelhos e equipamentos que ele próprio determinou e pelos quais é determinado, mas já há muito tempo perdeu a consciência de que este mundo é criação do homem" (p. 74).

A partir dessa perspectiva de engajamento que compreende a forma de inserção do sujeito na realidade fenomênica, que se apresenta a partir da totalidade material e cuja aparência está impregnada de ideologia, propomos como superação dialética: a construção crítica e reflexiva de engajamento. Nessa compreensão, o engajamento se constrói no processo epistemológico e político de superação da cotidianidade, da pseudoconcreticidade, por meio da educação crítica e da práxis política. Para a superação da relação cotidiana e fenomênica dos sujeitos com o outro e o mundo pela mediação de redes sociotécnicas, de maneira reificada, o desenvolvimento da

${ }^{6}$ Não é nosso objetivo aqui fazer um aprofundamento deste conceito. Para maiores informações, ver Bezerra, Schneider, Pimenta e Saldanha (2019). competência crítica em informação $(\mathrm{CCI})^{6}$, da crítica da mídia e da tecnoliteracia podem ser métodos fecundos para a educação política e a construção do engajamento crítico e reflexivo. Em linhas gerais, a CCI formula a crítica à visão instrumental de competência em informação e propõe "maior articulação entre o pensamento crítico e os estudos e práticas relacionados à competência em informação" (Schneider, 2019, p. 103). O desenvolvimento da CCI exige sete habilidades ou níveis fundamentais. Em primeiro lugar, em diálogo com as proposições de Agnes Heller, Schneider 
(2019) propõe a suspensão da cotidianidade, ou seja, "a concentração em um único problema ou conjunto de problemas" (p. 104). O segundo nível se refere ao domínio instrumental, às habilidades requeridas para uso dos dispositivos informacionais: equipamentos, códigos, sistemas de busca etc. O terceiro nível envolve a reflexão sobre as necessidades e gostos informacionais: a "necessidade de questionamento da própria noção de necessidade informacional, por parte de mediadores e usuários da informação" (p. 104). Em quarto lugar está a atitude questionadora diante da informação: a "necessidade de questionamento da relevância dos enunciados, bem como dos mecanismos e critérios sociotécnicos de atribuição de relevância aos enunciados, aos dados e aos metadados" (p. 106). O quinto nível é a atitude questionadora diante das fontes de informação. Em sexto lugar está o estudo da ética em informação, nas dimensões epistemológica, política e estética ou existencial. E o sétimo nível envolve o conhecimento das teorias sociais críticas e das teorias críticas da informação. Questionando a literacia como algo estático, Kellner e Kahn (2015) argumentam que a literacia está em constante mudança e evolução em resposta às "transformações sociais e culturais, bem como aos interesses das elites que controlam as instituições hegemônicas. Além disso, é uma parte crucial do processo de literacia que as pessoas entendam os códigos dominantes como hegemônicos" (p. 61).

Acrescentamos serem também fundamentais para o engajamento crítico o desenvolvimento da consciência política que, de acordo com Gramsci (1966), é a consciência de fazer parte de determinada força hegemônica, e a práxis interativa em aparelhos populares de hegemonia (Bastos, 2015). Propomos o conceito de aparelhos populares de hegemonia para designar organizações e instituições, cujos processos de formação política e produção simbólica contribuem para a construção de um projeto de poder popular. Para Gramsci, em última análise, este papel cabe ao partido. Nesse ínterim, Guido Liguori (2007) propõe que há nos Cadernos do cárcere "uma teoria 'materialista' da ideologia", pois a luta ideológica não se resume a "batalha de ideias", posto que essas ideias possuem uma base material, "articulam-se em aparelhos" (pp. 90-91). Dessa maneira, o sujeito consciente de si, graças à ideologia, concebida como lugar de construção da subjetividade, capaz de lutar contra a hegemonia adversária por outra hegemonia, deve apropriar-se dos próprios "aparelhos hegemônicos" ou "ideológicos".

INTERNET E SITES DE REDES SOCIAIS COMO SUPORTES PARA APARELHOS PRIVADOS DE HEGEMONIA

Na concepção de Estado ampliado ${ }^{7}$ de Gramsci, a sociedade política, correspondente às forças coercitivas e educadoras do Estado, soma-se à sociedade civil, que tem nas suas instituições, ou aparelhos privados de hegemonia - imprensa,
${ }^{7} \mathrm{O}$ conceito original de Gramsci é Estado integral; a expressão teoria ampliada do Estado foi cunhada por Christine BuciGlucksmann em 1975, em seu livro Gramsci e o Estado (Buci-Glucksmann, 1975/1980), a partir das reflexões de Gramsci. 
sindicatos, igrejas, movimentos sociais, partidos políticos, entidades de classe e organizações diversas -, os espaços por excelência de formação política e ideológica, questionando ou fortalecendo o bloco histórico estabelecido. À totalidade de equilíbrio do poder entre base e superestrutura, forças materiais e ideológicas, Gramsci (1966) dá o nome de "bloco histórico" (p. 52). Conforme Moraes (2010), os aparelhos privados de hegemonia funcionam como "caixas de ressonância de posições presentes nas pelejas ideológico-culturais" (p. 59).

Coutinho (1992) ressalta que a novidade na formulação de Gramsci não está tanto em relação ao conceito de hegemonia, desenvolvido inicialmente por Lênin, mas ao mostrar que a hegemonia, como "figura social" (p. 77), possui base material própria, espaço autônomo e específico de manifestação. Essa materialidade da hegemonia é objetificada pelos aparelhos privados, pela sociedade civil. Importante ressaltar que Marx e Engels (2012) já haviam destacado a sociedade civil como "palco da história", que abrange "toda troca material dos indivíduos dentro de uma determinada fase de desenvolvimento das forças produtivas” (p. 63). Com o desenvolvimento das forças produtivas, especialmente das ITCs, cremos ser relevante para nosso propósito aqui entender algumas características de funcionamento da internet e dos SRS como suportes tecnológicos para aparelhos privados de hegemonia. Importante destacar este aspecto: os aparelhos privados de hegemonia atuam mediando o engajamento dos sujeitos, de maneira articulada, dentro e fora das redes.

Em esforço intelectual crítico para atualizar a ideia gramsciana de aparelhos privados de hegemonia na sociedade civil contemporânea, Murilo César Ramos (2010) propõe a seguinte hierarquia, segundo a capacidade de projeção de poder das instituições:

a Empresa, ou seja, o conjunto ideológico dos preceitos que conformam o que também chamamos de mercado; as Instituições de comunicação, ou, como as tratamos mais comumente, a Mídia; o Grupo, conjunto de associações pessoais que mais influenciam nossos comportamentos; a Família; as Igrejas; a Escola; o Sindicato ou Associação, de trabalhadores ou empresariais; e o chamado Terceiro Setor. (p. 6)

Seguindo com sua argumentação, Ramos (2010) ratifica que empresa e mídia são os mais poderosos aparelhos privados de hegemonia, sendo as instituições midiáticas uma forma singular de empresa. O poder e singularidade da mídia, ainda de acordo com Ramos, estão na sua capacidade de produção e disseminação de conteúdos jornalísticos, informativos e de entretenimento "embebidos em sua virtual totalidade da lógica absoluta do consumo, que é a 
principal força ideologicamente reprodutora do capitalismo" (p. 6). Podemos fazer aproximação com a formulação de Schneider (2015), quando afirma que

se o principal vetor que norteia os fluxos informacionais das ITCs é a reprodução ampliada do capital e a manutenção da hegemonia política de determinados setores da classse dominante, é necessariamente isto que temos que engolir sob a forma de espetáculo. (p. 133)

Podemos ponderar a hierarquização proposta por Ramos (2010), sobretudo se considerarmos verdadeira a proposição de Williams (2005) de que as instituições educacionais são os principais agentes de transmissão e incorporação da cultura dominante, mas não há como não concordar com a avaliação de Ramos (2010) sobre a relação intrínseca entre empresa, mídia e capital.

A internet e os SRS funcionam como suporte tecnológico para os aparelhos privados de hegemonia de maneira diversa, complexa e contraditória, refletindo lutas sociais e políticas da sociedade. A inserção das instituições da sociedade civil como ator sociotécnico na web se dá conforme as regras, métricas e padrões discursivos de funcionamento da informação midiatizada, cuja circulação on-line é em grande parte mediada pelas empresas gigantes da internet. Esse aspecto nos leva a refletir sobre a materialidade desses atores sociotécnicos. Ora, se o que caracteriza os aparelhos privados de hegemonia é sua materialidade própria, ao atuarem na internet e SRS, as demais instiutições se hospedam em base material que não lhe pertence.

Os principais aparelhos privados de hegemonia que, pela sua base material, determinam em última análise as "regras do jogo" são as grandes empresas da internet, especialmente Google e Facebook. O que vai fazer diferença para as intituições atuarem nesse campo virtual será poder econômico, político, inteligência e capacidade técnica para operar conforme os imperativos do capital e a lógica algorítmica a estes submetida. Vamos destacar o aspecto da produção material das ITCs, que compõe uma totalidade, para depois discutirmos as especificidades dos atores sociotécnicos, com foco nas empresas e na lógica algorítmica. Marx (2011) salienta que não há produção em geral e nem produção universal, que a produção é sempre "um ramo particular da produção" ou uma totalidade, e cita como exemplo a agricultura, a pecuária ou a manufatura. Não obstante, a produção não é somente produção particular, é sempre "um certo corpo social, um sujeito social em atividade em uma totalidade maior ou menor de ramos de produção" (pp. 57-58). Na dialética marxiana, produção, distribuição, troca e consumo constituem uma totalidade, as "diferenças dentro 
de uma unidade" (pp. 75-76). Contudo, para Marx, a produção se sobrepõe aos outros momentos, é a partir dela que sempre recomeça o processo.

No século XIX, ao raciocinar sobre a maneira como os meios de transporte e comunicação do período manufatureiro logo passaram a ser obstáculos para a indústria moderna, Marx (2010) destaca que, além das radicais transformações no modo de construção dos navios a vela, "o sistema de transportes e comunicações foi progressivamente adaptado ao modo de produção de grande indústria com a introdução dos navios a vapor fluviais, das vias férreas, dos transatlânticos e do telégrafo" (p. 440). Levando a reflexão para o século XX, a crise dos modelos de desenvolvimento econômico, tanto do capitalismo como do estatismo, que motivaram sua reestruturação durante a década de 1970, tem origem no conflito entre a rigidez do chamado fordismo, o modo de produção em massa, e as crescentes necessidades da economia por flexibilidade administrativa e globalização do capital (Castells, 1999; Harvey, 1993). As ITCs tiverem papel central para a constituição da nova forma do capitalismo, flexível e rejuvenescido. Algumas características dessa nova forma de capitalismo são: "a globalização das principais atividades econômicas, flexibilidade organizacional e maior poder para o patronato em suas relações com os trabalhadores" (Castells, 1999, p. 411).

Os anos de 1984-1985 são de transição e ampliação da desregulamentação das telecomunicações, ou seja, privatizações, livre concorrência e facilitação ao livre mercado com base nas mudanças tecnológicas: digitalização, redes de alta performance, optoeletrônica, aumento da capacidade das memórias e diminuição dos custos (Mattelart, 2001). Com os esforços das grandes potências, norte-americanos, europeus e grandes empresas globais, as tecnologias da informação e da comunicação tornam-se a base para um rearranjo geoeconômico do mundo em torno da democracia de mercado. Ou, conforme Quiroga (2019), em diálogo com Sodré, temos "a centralidade da midiatização como um dos espaços por excelência de constituição da economia contemporânea” (p. 82). Dessa maneira, o processo de ampliação das possibilidades comunicativas gerado pelo desenvolvimento das forças produtivas é limitado pelo processo hegemônico do capital.

Nesse ínterim, há uma razão estrutural, econômica, para a limitação do potencial político e engajamento crítico com a mediação da internet e dos SRS. Assim como ocorreu com o desenvolvimento tecnológico e uso do rádio, que tinha potencial técnico no seu início para a comunicação crítica e emancipatória, para ser mais do que um aparelho comercial de distribuição de informação (Brecht, 2007), o potencial interativo e revolucionário da internet se choca com as relações de produção; relações de produção, com seu aspecto jurídico, que são as relações de propriedade (Marx, 2008), que limitam o potencial tecnológico da internet para a comunicação interativa, incorporando a tecnologia como mais 
uma peça da engrenagem do capital. De outra maneira, há um controle dos processos interativos pelo capital, o que potencializa o uso comercial da informação, sua utilização hegemônica como forma mercadoria, e são estabelecidos limites aos processos interativos com potenciais realmente transformadores.

Importante mencionar que as empresas e marcas mais valiosas do mundo compõem o segmento das ITCs. Em ranking da lista anual da Forbes, a Apple ocupa o posto de marca mais valiosa do mundo pela nona vez, avaliada em US\$205,5 bilhões. Google está em segundo lugar, com o valor de US\$167,7 bilhões, alta de 23\% (Badenhausen, 2019). O Google é líder absoluto do mercado de mecanismos de busca, com uma participação de $92 \%$ nos últimos 12 meses, de acordo com a StatCounter (a Bing tem 2,6\% e o Yahoo 1,9\%). A Microsoft (US\$123,5 bilhões) e a Amazon (US\$ 97 bilhões) completam o Top 4, ambas aumentaram mais de $20 \%$ em valor de mercado. O Facebook ocupa o quinto lugar no ranking, totalizando US\$ 88,9 bilhões, $6 \%$ menos em relação a 2018, sendo a única empresa no Top 10 a sofrer desvalorização. A publicidade corresponde ao maior faturamento da receita do Facebook, representando $92 \%$, o que soma US\$13,5 bilhões (alta de 33\% em 2018) (Selmi, 2018). Conquanto o foco principal da pesquisa de Astrid Mager (2012) seja o Google, podemos utilizar sua análise também para o Facebook. Segundo a autora, essas empresas correspondem ao novo modo de exploração do capitalismo que, conforme a acepção de Boltanksi e Chiapello (2009), atua em uma forma de exploração que se desenvolve no mundo conexionista, onde o lucro é realizado por operações econômicas em redes.

\section{MEDIAÇÃO ALGORÍTMICA DO ENGAJAMENTO}

$\mathrm{O}$ fato de a maneira facebookiana de conceber engajamento se refletir nas pesquisas da área de comunicação e informação lembra-nos do início das ciências da comunicação, nos Estados Unidos, e o assombro causado ao filósofo alemão Theodor Adorno (1995) quando se deparou com o método científico em comunicação praticado em solo norte-americano. Lazarsfeld e Stanton haviam aperfeiçoado o chamado program analyzer ou profile machine, batizado de analisador Lazarsfeld-Stanton, para os estudos do Princeton Radio Research Project. A máquina era encarregada de registrar as reações do ouvinte em termos de aprovação, aversão ou indiferença, a partir de, respectivamente, um botão verde à direita, um botão vermelho à esquerda, ou nenhum dos dois (Mattelart \& Mattelart, 2006). Adorno (1995) relata da seguinte maneira o seu impacto, após ouvir relatos sobre "Likes and dislikes study", coisa que representava pouco para ele: 
Mas entendi o suficiente para me dar conta de que se tratava de coleta de dados, dos passos da planificação no campo dos meios de comunicação de massas, em benefício, quer da indústria imediatamente, quer dos assessores culturais e agremiações semelhantes. Pela primeira vez, via diante de mim "administrative research" (investigação administrativa): hoje já não me recordo se foi Lazarsfeld quem cunhou esse conceito, ou se fui eu em meu assombro diante de um tipo de ciência orientada para o prático, coisa para mim insólita. (p. 144)

Talvez não sejamos tão críticos como Adorno, mas também nos causa assombro tratar engajamento a partir de interações mediadas por ferramentas de SRS, como botões de reações. Adorno (1995) traz outra relevante reflexão para criticarmos esta perspectiva de engajamento e, neste momento, entendermos o papel da ideologia dos algoritmos na formação do gosto dos sujeitos e do seu engajamento com determinada ideologia: a tese de que o gosto musical está sujeito à manipulação. Poderíamos expandir a reflexão para outras áreas da informação midiatizada: o gosto cultural, político ou, até mesmo, o científico. Precisamos nos ater ao "caráter já mediatizado do aparentemente imediato" (p. 158). Tiago Quiroga (2019) também contribui com nossa reflexão crítica à adoção da perspectiva facebookiana nas pesquisas da nossa área, quando argumenta que um dos resultados do processo da midiatização como "materialidade estrutural" do capitalismo contemporâneo é a "exportação do discurso organizacional para distintas instituições, sendo uma de suas consequências mais expressivas sua uniformização discursiva” (p. 83).

O que nos interessa particularmente sobre os algoritmos é o que Tarleton Gillespie (2018) chama de algoritmos de relevância pública que, por meio de procedimentos matemáticos, produzem e certificam conhecimento. O que, conforme Gillespie, traz implicações específicas ao selecionar o que é relevante a partir de "rastros das nossas atividades, preferências e expressões" (p. 97). Essa avaliação algorítmica possui uma lógica de conhecimento particular para definir conhecimento e identificar seus aspectos mais relevantes. "O fato de estarmos recorrendo a algoritmos para identificar o que precisamos saber é tão marcante quanto termos recorrido aos especialistas credenciados, ao método científico, ao senso comum ou à palavra de Deus" (p. 97). Gillespie sentencia que, em uma análise sociológica, é necessário investigar as escolhas humanas e institucionais por trás dos mecanismos. Nesse ínterim, vale destacar a dimensão ético-política desse processo de vigilância quase onipresente e onisciente, sob a gerência de instituições econômicas e estatais, no qual os algoritmos se alimentam inadvertidamente dos dados dos usuários com o objetivo, em última instância, de acumulação do capital. Christian Fuchs (2011) ressalta que a vigilância é uma 
relação social que envolve o poder disciplinar e diferencia o que denomina como tecnologias de vigilância (as forças produtivas da vigilância) e as estruturas sociais/societais de vigilância (que correspondem às relações de produção da vigilância). $\mathrm{O}$ autor alerta que reduzir a vigilância ao nível das tecnologias é uma "forma de reducionismo tecno-determinista e de fetichismo que reifica a vigilância e dessa forma destrói o potencial crítico do conceito" (p. 122).

A introdução do feed de notícias do Facebook em 2006, que proporciona personalização do conteúdo, conforme assinala a comunicação institucional da plataforma, marca a transformação na lógica de visibilidade e exposição dos usuários e foi adotado por outras plataformas da web, como Twitter, Instagram e Pinterest (Araujo, 2018). Araujo argumenta que o mecanismo do feed de notícias é definido por processos relacionais, de negociação, e destaca que a percepção do usuário sobre a funcionalidade é parte fundamental do processo. $\mathrm{O}$ autor vai formular o conceito de norma algorítmica, uma lógica punitiva baseada em menor ou maior visibilidade, que define o relacionamento entre produtores de conteúdo e o sistema de classificação do feed de notícias, discriminando conteúdos e comportamentos como legítimos ou não. Araujo elenca duas características principais dessa lógica: a partir de dados, estatísticas, comportamentos, entrevistas etc., ocorre uma série de "definições valorativas sobre conteúdos e comportamentos que devem ser banidos" (p. 14); e, sem segundo lugar, condicionam a visibilidade conforme as regras estabelecidas e atualizadas no serviço. Araujo conclui que o que é considerado normal dentro dessa lógica é o que gera, segundo o autor, engajamento genuíno: aquele conteúdo que faz os usuários interagirem, sem explicitamente solicitar que eles curtam ou compartilhem. A partir de argumentação de Taina Bucher, Jurno e DalBen (2018) abordam padrões de comportamento que emergem com os algoritmos: por recompensar certo tipo de comportamento, usuários e organizações tendem a formatar suas publicações de modo a gerar maior visibilidade e engajamento, o que implementa realidades materiais ao moldar a vida social, conforme as autoras. Como se pode notar, em ambas as pesquisas mencionadas não há problematização sobre a noção de engajamento.

Uma discussão central sobre o sistema de algoritmos e sua lógica é a relação entre relevância e popularidade, tema do artigo de Seth Finkelstein (2008). O autor chancela que a atividade de classificação de página é um processo carregado de valores e implicações sociais sérias. Seth Finkelstein explora três proposições em seu artigo. Primeiro, a pesquisa de páginas não é uma atividade democrática. Em segundo lugar, buscar por palavras em um motor de busca levanta a seguinte questão: ao pesquisar, queremos ver um retrato da sociedade ou como deveríamos ser? Em terceiro lugar, o fato de o sistema de buscas ser baseado 
${ }^{8}$ No original: "search engines are negotiated in a network of actors, interests and practices within contemporary frames of meaning, the capitalist ideology in particular". Esta e demais traduções do autor.

${ }^{9}$ No original: "capitalist spirit gets embedded in search algorithms by way of social practices".

${ }^{10}$ No original: "the results of the algorithmic calculation by a search engine come to reflect political struggles in society". na popularidade não constitui um modelo apropriado para a sociedade civil. Gillespie (2018) também raciocina que "relevante" é um julgamento "fluido e carregado de significados" (pp. 103-104). Mager (2012) considera que os "mecanismos de busca são negociados em uma rede de atores, interesses e práticas dentro de quadros de significado contemporâneos, a ideologia capitalista em particular"8 (p. 773). A autora identifica como principais atores sociotécnicos na configuração dos mecanismos de busca: redes de engenheiros, provedores de site e usuários e, em contexto mais amplo, concorrentes, mídia de massa, políticas e estruturas legais. Outro aspecto a ser destacado, conforme a análise da autora, é que o "espírito capitalista se encaixa nos algoritmos de busca por meio de práticas sociais"9 (p. 779). Ela avalia que nem os provedores nem os usuários devem ser vistos como vítimas dos mecanismos de busca, mas como agentes estabilizadores da tecnologia com suas práticas de marketing, busca e consumo, ora consciente ora inconsciente.

Seth Finkelstein (2008) desenvolve argumentação fundamental para nossa discussão ao raciocinar que os votos que geram relevância a uma página são como votos de acionistas, não de um cidadão comum, porque seu poder varia conforme blocos, facções e grupos de interesse. Dessa maneira, "os resultados do cálculo algorítmico por um mecanismo de pesquisa refletem as lutas políticas na sociedade"10 (p. 107). Podemos acrescentar, parafraseando Marx (2009), que se trata também de luta social, porque não há luta política que não seja também luta social. Como nos mostra Seth Finkelstein (2008), o mais provável é que os hiperlinks (e os algoritmos de popularidade associados) reflitam e reforcem hierarquias existentes. E a verdade deste fato possui uma lógica, como argumenta o autor: se a busca de informações retornasse com resultados perturbadores ou subversivos, haveria forte pressão para que o sistema fosse alterado. Acrescentamos que a interação mediada por SRS pode ser compreendida como interação especular, conforme definimos anteriormente (Bastos, 2018), um modo de interação mediada que reflete a identidade do usuário, tratado eminentemente como determinado perfil de público-alvo para anúncios publicitários. As bolhas criadas pelos filtros do Facebook, por exemplo, pelo sistema de algoritmos EdgeRank, resultam em "processo de personalização que inibe acesso a conteúdos divergentes" (Bittencourt, 2015, p. 127). Dessa maneira, a não ser que se busquem formas de burlar os algoritmos - como passar a curtir páginas cujo conteúdo divirja dos seus interesses, para que possa acompanhar as discussões, ou mesmo entrar eventualmente para tentar interagir com este público -, a interação especular prevalecerá. 


\section{CONSIDERAÇÕES FINAIS}

Todas as nossas instituições formadoras de ideologia consideram que a sua principal tarefa é a de manter despropositado o papel da ideologia, em consonância com um conceito de cultura, segundo o qual a formação cultural já estaria concluída e a cultura não careceria de nenhum esforço criativo continuado. Não cabe aqui investigar em razão de que interesses essas instituições são inconsequentes; mas, se um invento técnico, dotado de uma aptidão tão natural para as decisivas funções sociais, propõe-se um esforço tão desesperado para permanecer inconsequente, envolvido no entretenimento mais inofensivo, então surge de modo incontornável a questão sobre a possibilidade de se defrontarem as forças da desconexão por meio da organização dos desconectados. (Brecht, 2007, p. 229)

Desde os debates históricos sobre engajamento nos campos da arte e da ciência, passando pela virada discursiva em que o caráter político do conceito é expropriado para dar lugar ao sentido corporativo e tecnicista do termo, que se torna dominante, um par conceitual permanece indissoluvelmente ligado ao engajamento: ideologia. Terry Eagleton (1997) afirma sarcasticamente que ideologia é como o "mau hálito" (p. 16), algo que outra pessoa tem. Como afirmamos que se trata de um par conceitual, logo, significam-se reciprocamente, poderíamos dizer o mesmo de engajamento. Eric Hobsbawm (2013) argumenta que o engajamento "implica um adversário" (p. 178), fato que pode ser localizado em embates científicos e políticos. Em nossa exposição priorizamos o caráter de classe do fenômeno, ou seja, adotando o postulado de Hobsbawm, tratamos fundamentalmente da crítica ao uso econômico e político da prática e do conceito de engajamento para a acumulação do capital. Para isso, nosso percurso teórico buscou desvelar e cotejar os pilares conceituais do sentido dominante de engajamento com a reflexão epistemológica crítica, com base em ciências da comunicação e na teoria filosófica e política marxiana. No capitalismo contemporâneo, com a imbricação entre mídia e capital financeiro, a midiatização opera como lógica estruturante e totalizante. A maneira como sorrateiramente o sentido dominante de engajamento adentra as pesquisas e o linguajar cotidiano da comunicação e informação denota a "uniformização discursiva” (Quiroga, 2019 , p. 83) nivelada pela lógica econômica e organizacional. A disputa de sentido acerca dos conceitos de engajamento é ainda mais acirrada na área da comunicação porque esta lida mais diretamente com o modo como as diferentes atividades profissionais, como o marketing, a publicidade, o jornalismo e as relações públicas, criam, acionam e publicizam códigos profissionais e corporativos, contribuindo para sustentar seu sentido dominante. 
Ao definirmos engajamento como a vinculação social, afetiva e gustativa do sujeito com determinada ideologia, destacamos que se trata da dimensão comunicacional e sensível atuante no engendramento da hegemonia. Como traduz a anedota de Terry Eagleton (1997), esse processo por vezes não é consciente para o sujeito, que pode enxergar ideologia-engajamento no outro, mas não em si mesmo, realidade que pode ser superada com o desenvolvimento da consciência política, da educação crítica e do engajamento crítico. Ao tratar da evolução do conceito de ideologia no pensamento de Marx, Eagleton afirma que ideologia passa a ser menos uma questão de inversão da realidade na mente do que a "mente refletir uma inversão real" (p. 83). Dessa maneira, não se trata primariamente da consciência, mas da ancoragem da ideologia "nas operações econômicas cotidianas do sistema capitalista” (p. 83), caracterizadas, em última análise, pelo fetichismo da mercadoria, o que se aproxima da concepção materialista de ideologia de Gramsci, em que os aparelhos de hegemonia são os espaços por excelência de produção e reprodução ideológica.

A citação de Brecht, inserida na epígrafe desta seção, é de quase cem anos atrás e permanece bastante atual. A organização dos desconectados, a que se refere Brecht, pode ser compreendida mais superficial e especificamente como a organização de sujeitos alijados do acesso ao dispositivo técnico-comunicacional, o rádio ou a internet, ou de forma mais profunda e abrangente, pode significar a aliança política das classes populares, desconectadas, exploradas e expropriadas, o que exige o engajamento com determinada ideologia, com a ética de um projeto de poder popular. Como bem observou Celso Frederico (2007),

Brecht não tinha ilusões com relação à capacidade de neutralização e cooptação do sistema, tendo observado como marxista, muito antes que Adorno, o primado da produção sobre o consumo dos bens simbólicos ao afirmar que "é a engrenagem que elabora o produto para consumo". (p. 217)

Além disso, observou a força revolucionária na reunião dos conhecimentos teóricos do teatro épico e do potencial tecnológico da nascente radiodifusão. Ambos caminhavam juntos para realizar o "imperativo da interatividade" (p. 217). Também não temos ilusões sobre a maneira como o potencial transformador da práxis interativa e do desenvolvimento das forças produtivas é cooptado pelo capital, mas entendemos que a reflexão marxiana aqui desenvolvida contribui para um olhar mais crítico sobre engajamento, seus limites e potenciais teóricos e políticos. $\mathbf{M}$ 


\section{REFERÊNCIAS}

Adorno, T. (1995). Palavras e sinais: Modelos críticos 2. Petrópolis, RJ: Vozes.

Araujo, W. F. (2018). A construção da norma algorítmica: Análise dos textos sobre o feed de notícias do Facebook. E-compós, 21(1), 1-21. doi: 10.30962/ec.1402 Arcas, M. (2019, 4 de fevereiro). Facebook completa 15 anos cercado por polêmicas, mas cheio de dinheiro. UOL. Recuperado de https://bit.ly/2wkoT3A

Badenhausen, K. (2019, 22 de maio). As 100 marcas mais valiosas do mundo em 2019. Forbes. Recuperado de https://bit.ly/2RmxQ3A

Bastos, P. N. (2015). Marcha dialética do MST: Formação política entre campo e cidade (Tese de doutorado, Universidade de São Paulo). doi: 10.11606/T.27.2015.tde-29062015-151022

Bastos, P. N. (2018, setembro). Comunicação, interação e engajamento: Fronteiras epistemológicas e alcances políticos. Trabalho apresentado no $41^{\circ}$ Congresso Brasileiro de Ciências da Comunicação, Joinville, SC. Recuperado de http:// portalintercom.org.br/anais/nacional2018/resumos/R13-1095-1.pdf

Becker, H. (1996). A escola de Chicago. Mana, 2(2), 177-188. doi: 10.1590/ S0104-93131996000200008

Bezerra, A. C., Schneider, M., Pimenta, R. M., \& Saldanha, G. S. (Orgs.). (2019). iKritika: Estudos críticos em informação. Rio de Janeiro, RJ: Garamond.

Bittencourt, M. C. A. (2015). Midiatização do ativismo e jornalismo digital: O impacto dos filtros do Facebook nos processos de produção e circulação de conteúdos de coletivos midiáticos. Revista Latinoamericana de Ciencias de la Comunicación, 12(22), 122-133. Recuperado de https://bit.ly/2Lntg1O

Blumer, H. (1980). A natureza do interacionismo simbólico. In C. D. Mortensen (Org.), Teoria da comunicação: Textos básicos (pp. 119-137). São Paulo, SP: Mosaico.

Boltanski, L., \& Chiapello, Ė. (2009). O novo espírito do capitalismo. São Paulo, SP: Martins Fontes.

Braga, J. L. (2006a). A sociedade enfrenta sua mídia: Dispositivos sociais de crítica midiática. São Paulo, SP: Paulus.

Braga, J. L. (2006b). Mediatização como processo interacional de referência. Animus, 5(10), 9-35. Recuperado de https://bit.ly/3bvdAE8

Brecht, B. (2007). O rádio como aparato de comunicação: Discurso sobre a função do rádio. Estudos Avançados, 21(60), 227-232. Recuperado de https://bit.ly/2RlRE7h

Buci-Glucksmann, C. (1980). Gramsci e o Estado. Rio de Janeiro, RJ: Paz e Terra. (Obra original publicada em 1975) 
Bylaardt, C. O. (2013). Arte engajada e arte autônoma no pensamento de Theodor Adorno. Pandaemonium Germanicum, 16(22), 84-100. doi: 10.1590/S1982-88372013000200005

Castells, M. (1999). A era da informação: Vol. 1. Economia, sociedade e cultura. São Paulo, SP: Paz e Terra.

Corrêa, D. S., \& Dias, R. C. (2016). A crítica e os momentos críticos: De la justification e a guinada pragmática na sociologia francesa. Mana, 22(1), 67-99. doi: 10.1590/0104-93132016v22n1p067

Coutinho, C. N. (1992). Gramsci: Um estudo sobre seu pensamento político. Rio de Janeiro, RJ: Campus.

Eagleton, T. (1997). Ideologia: Uma introdução. São Paulo, SP: Boitempo.

Fausto Neto, A. (2008). Fragmentos de uma "analítica" da midiatização. MATRIZes, 1(2), 89-105. doi: 10.11606/issn.1982-8160.vli2p89-105

Ferrara, L. (2003). Epistemologia da comunicação: além do sujeito e aquém do objeto. In M. I. V. LOPES (Org.), Epistemologia da comunicação (pp. 55-67). São Paulo, SP: Loyola.

Finkelstein, S. (2008). Google, links, and popularity versus authority. In J. Turow \& L. Tsui (Eds.), The hyperlinked society: Questioning connections in the Digital Age (pp. 104-120). Ann Arbor, MI: University of Michigan Press.

Frederico, C. (2007). Brecht e a "Teoria do rádio". Estudos Avançados, 21(60), 217-226. doi: 10.1590/S0103-40142007000200017

Freire, P. (1977). Extensão ou comunicação? Rio de Janeiro, RJ: Paz e Terra.

Fuchs, C. (2011). Como podemos definir vigilância? MATRIZes, 5(1), 109-136. doi: 10.11606/issn.1982-8160.v5ilp109-136

Gillespie, T. (2018). A relevância dos algoritmos. Parágrafo, 6(1), 95-121. Recuperado de https://bit.ly/2WNxUvm

Gramsci, A. (1966). Concepção dialética da história. Rio de Janeiro, RJ: Civilização Brasileira.

Gramsci, A. (1968). Os intelectuais e a organização da cultura. Rio de Janeiro, RJ: Civilização Brasileira.

Grohmann, R. (2017, junho). A noção de engajamento: Sentidos e armadilhas para os estudos de recepção. Trabalho apresentado no XXVI Encontro Anual da Compós, Faculdade Cásper Líbero, São Paulo, SP. Recuperado de https://bit.ly/2JROPXm

Harvey, D. (1993). A condição pós-moderna. São Paulo, SP: Loyola.

Heller, A. (2004). O cotidiano e a história. São Paulo, SP: Paz e Terra.

Hjarvard, S. (2014). Midiatização: Conceituando a mudança social e cultural. MATRIZes, 8(1), 21-44. doi: 10.11606/issn.1982-8160.v8i1p21-44

Hobsbawm, E. J. (2013). Sobre história. São Paulo, SP: Companhia das Letras. 
Jurno, A. C., \& DalBen, S. (2018). Questões e apontamentos para o estudo de algoritmos. Parágrafo, 6(1), 17-29. Recuperado de https://bit.ly/2yBAZGi

Kellner, D., \& Kahn, R. (2015). Reconstruindo a tecnoliteracia: Uma abordagem de múltiplas literacias. Comunicação \& Educação, 20(2), 57-82. doi: 10.11606/ issn.2316-9125.v20i2p57-82

Kosik, K. (1976). Dialética do concreto. Rio de Janeiro, RJ: Paz e Terra.

Liguori, G. (2007). Roteiros para Gramsci. Rio de Janeiro, RJ: Editora UFRJ. Lukács, G. (1974). História e consciência de classe. Porto, Portugal: Escorpião. Mager, A. (2012). Algorithmic ideology: How capitalist society shapes search engines. Information, Communication \& Society, 15(5), 769-787. doi: 10.1 080/1369118X.2012.676056

Marx, K. (2008). Contribuição à crítica da economia política. São Paulo, SP: Expressão Popular.

Marx, K. (2009). Miséria da filosofia: Resposta à filosofia da miséria, do Sr. Proudhon. São Paulo, SP: Expressão Popular.

Marx, K. (2010). O capital: Crítica da economia política (Vol. 1). Rio de Janeiro, RJ: Civilização Brasileira.

Marx, K. (2011). Grundrisse: Manuscritos econômicos de 1857-1858: Esboços da crítica da economia política. São Paulo, SP: Boitempo.

Marx, K., \& Engels, F. (2012). A ideologia alemã. São Paulo, SP: Martin Claret. Mattelart, A. (2001). História da sociedade da informação. São Paulo, SP: Loyola. Mattelart, A., \& Mattelart, M. (2006). História das teorias da comunicação (14a ed.). São Paulo, SP: Loyola.

Mattos, M. Â., Janotti, J., Jr., \& Jacks, N. (Orgs). (2012). Mediação \& midiatização. Salvador, BA: Edufba.

Mattos, M. Â., \& Villaça, R. C. (2012). Interações midiatizadas: Desafios e perspectivas para a construção de um capital teórico. Revista Comunicação Midiática, 7(1), 22-39. Recuperado de https://bit.ly/3bw3AL9

Mészáros, I. (1993). Filosofia, ideologia e ciência social: Ensaios de negação e afirmação. São Paulo, SP: Ensaio.

Moraes, D. (2000). A hegemonia das corporações de mídia no capitalismo global. Recuperado de http://www.bocc.ubi.pt/pag/moraes-denis-hegemonia.html

Moraes, D. (2010). Comunicação, hegemonia e contra-hegemonia: A contribuição teórica de Gramsci. Revista Debates, 4(1), 54-77. doi: $10.22456 / 1982-5269.12420$

Pariser, E. (2012). O filtro invisível: O que a internet está escondendo de você. Rio de Janeiro, RJ: Zahar.

Quiroga, T. (2019). Midiatização e o entendimento desonerado. InMediaciones de la Comunicación, 14(2), 79-95. doi: 10.18861/ic.2019.14.2.2915 
Ramos, M. C. (2010, maio). Crítica a um Plano Nacional de Banda Larga: Uma perspectiva da economia política das políticas públicas. Trabalho apresentado na $4^{\text {a }}$ Conferência Acorn-Redecom, Brasília, DF.

Recuero, R. (2013, 7 de março). Engajamento x audiência no Facebook: Uma breve discussão. Recuperado de https://bit.ly/2RGQ6oQ

Santos, R. A. (2019). Práticas e discursos de engajamento: Estratégia do capitalismo. Curitiba, PR: Appris.

Sartre, J.-P. (2004). Que é a literatura? São Paulo, SP: Ática. (Obra original publicada em 1948)

Schneider, M. (2015). A dialética do gosto: Informação, música e política. Rio de Janeiro, RJ: Circuito.

Schneider, M. (2019). CCI/7: Competência crítica em informação (em 7 níveis) como dispositivo de combate à pós-verdade. In A. C. Bezerra, M. Schneider, R. M. Pimenta, \& G. S. Saldanha (Orgs.), iKritika: Estudos críticos em informação (pp. 73-116). Rio de Janeiro, RJ: Garamond.

Selmi, P. (2018, 30 de outubro). Lucro do Facebook sobe $9 \%$ no $3^{\circ}$ trimestre, para U\$ 5,1 bilhões. Valor Econômico. Recuperado de https://glo.bo/2Rns4Pr

Sodré, M. (2002). Antropológica do espelho: Uma teoria da comunicação linear e em rede. Petrópolis, RJ: Vozes.

Sodré, M. (2014). A ciência do comum: Notas para o método comunicacional. Petrópolis, RJ: Vozes.

Thompson, J. B. (2002). A mídia e a modernidade: Uma teoria social da mídia (12a ed.). Petrópolis, RJ: Vozes.

Thompson, J. B. (2018). A interação mediada na era digital. MATRIZes, 12(3), 17-44. doi: 10.11606/issn.1982-8160.v12i3p17-44

Toaldo, M. M, \& Rodrigues, A. I. (2015, setembro). Interação e engajamento entre marcas e consumidores/usuários no Facebook. Trabalho apresentado no XXXVIII Congresso Brasileiro de Ciências da Comunicação, Rio de Janeiro, RJ. Recuperado de https://bit.ly/2Kfdqpe

Williams, R. (2005). Base e superestrutura na teoria cultural marxista. Revista USP, (66), 210-224. doi: 10.11606/issn.2316-9036.v0i66p209-224

Wolf, M. (2006). Teorias da comunicação (9a ed.). Lisboa, Portugal: Presença.

Zuckerberg, M. (2019, 24 de janeiro). Um olhar sobre o modelo de negócio do Facebook. Folha de S.Paulo. Recuperado de https://bit.ly/2USfHwU

Artigo recebido em 29 de abril de 2019 e aprovado em 25 de março de 2020. 